San Jose State University

SJSU ScholarWorks

\title{
Evaluation of Student Perceived Self-Efficacy With the Implementation of a Problem-Based Learning Module
}

Joel David Romero

San Jose State University

Follow this and additional works at: https://scholarworks.sjsu.edu/etd_projects

Part of the Other Nursing Commons

\section{Recommended Citation}

Romero, Joel David, "Evaluation of Student Perceived Self-Efficacy With the Implementation of a ProblemBased Learning Module" (2007). Master's Projects. 812.

DOI: https://doi.org/10.31979/etd.79h3-jbyb

https://scholarworks.sjsu.edu/etd_projects/812

This Master's Project is brought to you for free and open access by the Master's Theses and Graduate Research at SJSU ScholarWorks. It has been accepted for inclusion in Master's Projects by an authorized administrator of SJSU ScholarWorks. For more information, please contact scholarworks@sjsu.edu. 


\section{SAN JOSE STATE UNIVERSITY \\ SCHOOL OF NURSING \\ MASTER'S PROGRAM PROJECT OPTION (PLAN B) \\ PROJECT SIGNATURE FORM}

STUDENT NAME Joel D. Romero

SEMESTER ENROLLED

TITLE OF PROJECT Evaluation of Student Perceived Self-Efficacy With

the Implementation of a Problem-Based Learning Module

NAME OF JOURNAL Nurse Educator

The project and the manuscript have been successfully completed and meet the standards of the School of Nursing University. The project demonstrates the application of professional knowledge, clinical expertise, and scholarly thinking. An abstract of the project and two copies of the manuscript are attached.

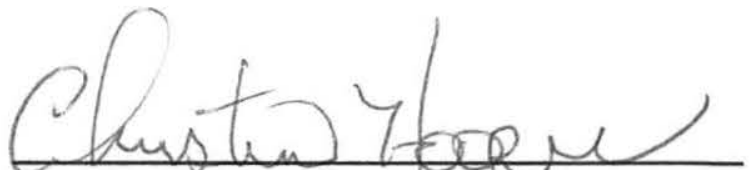

ADVISOR'S SIGNATURE

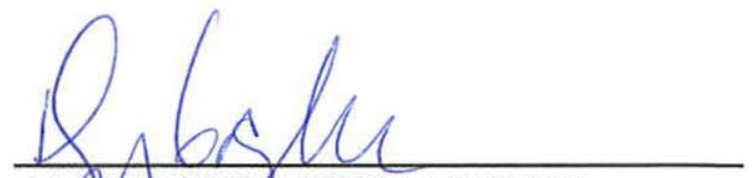

ADVISOR'S SIGNATURE

Please submit the form to the Graduate Coordinator. Attach abstract, two copies of the manuscript, and the documentation of submission to the journal (i.e., postal receipt). 


\begin{abstract}
To facilitate the graduation of competent registered nurses, healthcare educators must create learning environments that foster content expertise, problem solving, collaboration, and refined learning skills. Although countless teaching strategies are in existence today, problem-based learning (PBL) has revealed noteworthy potential in healthcare education. In PBL, complex, reality-based problems are used as motivation for students to identify salient concepts, gather data, and ultimately work through posed problems. Considerable evidence supports the use of PBL as a method to promote learning, though examining knowledge alone cannot always assess actual behavioral performance. To ascertain the likelihood learned concepts would be utilized in practice, we can evaluate perceived selfefficacy. According to Bandura, self-efficacy is the degree to which an individual believes that a behavior can be successfully performed to produce a desired outcome. Information learned provides a foundation for performance to transpire, but in the absence of self-efficacy performance may not even be attempted. This study examined the relationship between PBL and perceived self-efficacy. Using a quasi-experimental, non-equivalent control group design, self-efficacy was measured using Schwarzer and Jerusalem's General Self-Efficacy Scale. The study found that the perceived selfefficacy of undergraduate nursing students who participated in a PBL skills laboratory module were significantly higher than their counterparts who studied the same topic in a class not employing PBL.
\end{abstract}

By: Joel Romero, Dr. Christine Hooper, \& Debrah Gaylle 


\title{
EVALUATION OF STUDENT PERCEIVED SELF-EFFICACY \\ WITH THE IMPLEMENTATION OF A \\ PROBLEM BASED LEARNING MODULE
}

\author{
A Research Project \\ Presented to \\ The Faculty of the Division of Health Professions \\ San Jose State University
}

\author{
In Partial Fulfillment \\ of the Requirements for the Degree \\ Master of Science
}

By

Joel David Romero RN, BSN, CCRN

Christine Hooper RN, PhD

Debrah Gaylle RN, MSN

May 16, 2007 


\begin{abstract}
To facilitate the graduation of competent registered nurses, healthcare educators must create learning environments that foster content expertise, problem solving, collaboration, and refined learning skills. Although countless teaching strategies are in existence today, problem-based learning (PBL) has revealed noteworthy potential in healthcare education. In PBL, complex, reality-based problems are used as motivation for students to identify salient concepts, gather data, and ultimately work through posed problems. Considerable evidence supports the use of PBL as a method to promote learning, though examining knowledge alone cannot always assess actual behavioral performance. To ascertain the likelihood learned concepts would be utilized in practice, we can evaluate perceived self-efficacy. According to Bandura, self-efficacy is the degree to which an individual believes that a behavior can be successfully performed to produce a desired outcome. Information learned provides a foundation for performance to transpire, but in the absence of self-efficacy performance may not even be attempted. This study examined the relationship between PBL and perceived self-efficacy. Using a quasi-experimental, non-equivalent control group design, self-efficacy was measured using Schwarzer and Jerusalem's General Self-Efficacy Scale. The study found that the perceived self-efficacy of undergraduate nursing students who participated in a PBL skills laboratory module were significantly higher than their counterparts who studied the same topic in a class not employing PBL.
\end{abstract}

\title{
Research Problem
}

Professionals work in an environment of constant innovation and change prompting educators to create settings that foster content expertise, problem solving, collaboration, and refined learning skills (1). Particularly, nurse educators must adhere to rigorous guiding principles depicted by the National League for Nursing (NLN). Select NLN standards include: (a) utilization of various teaching techniques, (b) employment of evidence-based teaching strategies, and (c) facilitating student development of critical thinking (2). Innovative pedagogical approaches such as problem-based learning (PBL) may assist faculty in achieving these various academic outcomes. PBL is an interactive, evidence-based approach to 
instruction that fosters the development of analytical skills, critical thinking, collaboration, and communication skills (3). Extensive research exists examining diverse facets of PBL, though certain elements of its application remain relatively unexplored.

In the promotion of learning, the effectiveness of PBL as a pedagogical tool is well documented. However, pure knowledge acquisition does not necessarily translate to actual performance in the practice setting. Information learned provides a foundation for performance to transpire, but in the absence of self-efficacy, performance may not even be attempted (1). According to Bandura $(4,5)$, there exists a distinct difference between possessing skills and the ability to utilize them effectively under diverse circumstances. Nurse educators are not only mandated to facilitate learning, but to also ensure that knowledge attained is safely applied to clinical practice. A comprehensive investigation of the relationship between PBL and selfefficacy in undergraduate education is currently missing from the literature (1). Therefore, the purpose of this study was to examine the effect of PBL on baccalaureate nursing students' perceived self-efficacy. By beginning to fill this knowledge gap, health educators will gain additional insight into PBL further aiding in the selection of appropriate teaching strategies.

\section{Research Question}

The question developed to add to our current knowledge and guide the research was as follows: Will the implementation of a PBL module in an undergraduate nursing course increase student general perceived self-efficacy? The focus of the research therefore, was to identify if a positive relationship existed between the two germane learning theories. Direction of the research question was gleaned from Dunlap's work examining an analogous phenomenon. Finding that PBL increased student self-efficacy for undergraduate computer science students (1), it was plausible that a comparable outcome would be achieved in an undergraduate nursing setting. Therefore, we hypothesized that indeed students who participated in a PBL module would exhibit increased perceived self-efficacy when compared to those who utilized an similar learning module not employing PBL. 


\section{Background Literature Review}

Problem-Based Learning

Traditional educational techniques have relied heavily on the dissemination of information to a passive audience $(6,7)$. In our rapidly changing job market, where skills today are outdated tomorrow, this approach to instruction is obsolete warranting a response from educators (6). In order to prepare competent graduates, teaching strategies must foster problem-solving skills, critical thinking, independent analysis, effective communication, collaboration, reflection, and empowerment (6-9). PBL is an alternative to traditional lecturing techniques that addresses these various pedagogical recommendations in the promotion of optimal student outcomes.

PBL is a student-centered teaching approach developed in the early $20^{\text {th }}$ century. In the 1930 s, John Dewey designed PBL as a discovery method to pedagogy that promoted critical thinking (10). John Dewey's method was further refined by the seminal work of Jerome Bruner and Jean Piaget in the 1960s (10). Medical schools were one of the first health sciences to adopt PBL as a major teaching approach. For over three decades hundreds of medical schools throughout the world have utilized PBL, though as of the year 2000, only seven nursing schools in the U.S. were included in PBL literature (10).

The PBL method is inquiry-based instruction designed to achieve various student outcomes. In PBL, complex, reality-based case scenarios are used as motivation for students to identify and research salient concepts and work through posed problems (3). PBL adds to the traditional case study approach by emphasizing the development of reasoning and communication skills rather than solely focusing attention on the illustration of a main issue (3). Students encounter a real-life problem, identify current knowledge, obtain additional relevant information, participate in self-study, analyze the problem using newly acquired data, and communicate their findings to others $(1,3,6,10,11)$. PBL cases provide students the opportunity to experiment with potential solutions for situations encountered in reality within the safety of a classroom (7). The objective of the PBL process is to prepare students for professional practice by developing selfdirected learning, critical thinking, clinical reasoning, and lifelong learning skills $(1,6,11)$. 
A number of recent studies support the efficacy of PBL as a valuable undergraduate teaching strategy. Authors examining student-centered teaching frequently support the employment of PBL in addition to, or in place of, classical lecturing techniques $(1,8,11)$. When compared to traditional teaching strategies, $\mathrm{PBL}$ has been found to be equally or more effective in promoting knowledge retention (12). Studies have revealed that PBL generates equivocal objective test scores when measured against lecturing strategies and in some cases scores exceeded those of lecturing $(6,8)$. Students in PBL programs have also displayed a greater sense of structural and psychological empowerment when compared to their counterparts involved in teacher centered instruction (9). Additional advantages commonly cited in the utilization of PBL include increased levels of motivation toward learning, improved student perceptions as self-directed learners, and assistance in learning complex concepts $(8,11,13)$.

Self-Efficacy

Considerable literature espouses the use of PBL as a method to promote learning, although examining knowledge alone cannot always assess actual behavioral performance. To ascertain the likelihood learned concepts would be utilized in practice, we can evaluate perceived self-efficacy. Self-efficacy is the degree to which an individual believes that a behavior can be successfully performed to produce a desired outcome $(4,5)$. Nursing research has shown a clear correlation between increased self-efficacy and successful skill performance (14). Self-efficacy expectations and outcome expectations are the two major components of the self-efficacy theory. Self-efficacy expectations are personal evaluations of one's ability to successfully complete a given task while outcome expectations are judgments of what will occur if a task is accomplished $(4,5)$. According to Bandura $(4,5)$, outcome expectations are significantly influenced by selfefficacy expectations. Students exhibit a tendency to avoid situations that exceed their coping abilities but are conversely more likely to become involved in activities when a degree of self-efficacy is present $(4,5)$. 
Problem-Based Learning in Relation to Self-Efficacy

According to Bandura $(4,5)$, self-efficacy expectations are based on the following four information sources:

(a) performance accomplishments, (b) vicarious experience, (c) verbal persuasion, and (d) emotional arousal. Participant modeling and self-directed experiences promote learner performance accomplishments $(4,5)$. In PBL, modeling is achieved through guided group discussion while independent data collection and open student-instructor dialogue foster self-directed learning experiences. Bandura $(4,5)$ defined vicarious experience as the observation of successful task performance by others in the absence of adverse consequences. An inherent goal of PBL is the acquisition and sharing of new knowledge among peers in an environment devoid of punitive outcomes. Verbal persuasion is the process of leading a student, through suggestion, into believing that a task can be completed successfully $(4,5)$. In PBL, positive reinforcement from instructors and peers addresses verbal persuasion. Lastly, emotional arousal refers to the influence of stress generated by threatening experiences on student expectations $(4,5)$. The small group-learning environment of PBL reduces the audience size and promotes an increased level of teacherstudent interactions which in turn may decrease aversive student emotional arousal.

As described, a comparison of elements composing PBL and self-efficacy suggests the existence of a potential relationship between the two theories; although, empirical research supporting this assumption remains nearly absent. Only one recent study could be found that evaluated the effects of PBL on students' perceived self-efficacy. In 2005, Dunlap (1) examined changes in student perceived self-efficacy while involved in a PBL instructional environment. Using pretest and posttest assessments, Dunlap (1) identified a significant positive increase in student perceived self-efficacy when PBL was employed.

In nursing education, utilizing strategies that facilitate self-efficacy are vital to promoting successful skill accomplishments. Increased self-efficacy is compellingly associated with successful behavioral performance $(4,5)$. Dunlap's $(1)$ research was the only current study found that supported PBL as an 
effective instructional strategy when self-efficacy is measured. Therefore, justification for the current research was reinforced by the need to further explore the relationship between PBL and self-efficacy in undergraduate education.

\section{Conceptual Framework}

The conceptual framework for the research study was Bandura's theory of self-efficacy. Self-efficacy is based on social cognitive dimensions where learning is achieved via social processes between educators and students, interactions with the larger social world, and experience (15). The four sources of experience according to the social cognitive theory are direct experience, vicarious experience, judgments by others, and knowledge derived by inference $(16)$. Bandura $(4,5)$ explained that various cognitive processes beyond knowledge acquisition play a significant role in new behavioral patterns. In pedagogy, the degree of selfefficacy a student possesses may provide insight into the likelihood that learned behaviors would be acted upon. Bandura $(4,5)$ surmised that efficacy expectations determine whether behaviors will be initiated, the degree of effort employed, and duration of behaviors when an individual is involved in challenging situations. Therefore, the more self-efficacy an individual possesses, the higher the likelihood learned behaviors would be performed $(4,5)$.

\section{Methods}

Research Design

The research methodology selected for the study was a quasi-experimental, non-equivalent control group design. This approach facilitated the examination of change by assessing self-efficacy before and after employment of a PBL module. Nonprobability convenience sampling was the method utilized for subject selection. Participants selected were undergraduate nursing students attending the same semester and course to maintain homogeneity. 
Setting

The chosen site for implementation of the research was San Jose State University. Familiarity with the undergraduate curriculum facilitated the selection of a nursing course that best fit the study design. Additionally, creation of the PBL module and the applicability of academic content were enhanced by receiving input from experienced faculty. Finally, the university did not utilize PBL as a major pedagogical strategy for undergraduate nursing education. This last aspect increased the likelihood that students had not yet formally experienced PBL in their nursing curricula.

Subjects and Sampling

Junior level nursing students enrolled in the skills laboratory were the targeted study population. The semester five nursing laboratory, Nursing 155, was the final skills course in San Jose State Universities' registered nursing program. Students were familiar with the expectations associated with nursing education thus controlling for some academic related confounding variables. The PBL module was a modification of the currently used central venous catheter section of the course (Appendix A). Upon university and instructor approval, formal consent was obtained from all students choosing to participate. Anticipated risks and discomforts for participants were absent, and no unforeseen complications were encountered.

\section{Instrument}

Student perceptions were measured using Schwarzer and Jerusalem's General Self-Efficacy Scale (Appendix B). The tool was a ten-item scale that assessed individual beliefs in one's ability to cope with novel or challenging circumstances (17). The self-administered scale required respondents to indicate the extent to which each statement applied to them on a continuum of 1 which indicates 'Not true at all' to 4 representing 'Exactly true'. Summed scores fell within a range of ten as a minimum to forty as a maximum. The greater an individual's general perceived sense of self-efficacy, the higher the score (17). Accumulated data presented by Schwarzer (17) of 1,660 adults revealed a mean score of 29.28 . Ratings 
that supported a high degree of internal consistency using the General Self-Efficacy Scale have been found with alphas ranging from 0.82 to 0.93 (17).

\section{Study Procedures}

The study warranted subject participation in a number of research related activities. The control group received instruction according to the existing Nursing 155 course curriculum. In the experimental group, students were randomly assigned to one of two learning teams. Division into smaller work groups was necessary to ensure the most effective delivery of the PBL lesson. In PBL, students work in small teams to bring together their collective skills of acquiring, communicating, and processing new information (3). Over a period of three weeks, each group participated in separate one-half hour teaching sessions during scheduled class time.

The first week, prior to the module, all students completed Schwarzer and Jerusalem's General SelfEfficacy Scale. Following the baseline efficacy assessment, the PBL module was introduced to the experimental group and discussion commenced. During week two, the experimental group reconvened to discuss accumulated data and to uncover new issues. In the third and final session, groups discussed resolution of the issue in addition to summarizing knowledge gained. When the experimental and control groups completed their assigned modules, students were once again asked to complete the General SelfEfficacy Scale in addition to a brief demographic survey (Appendix C).

\section{Results}

Data analysis identified the existence of a statistically significant difference in perceptions between students in the experimental group and control group (Table 1). Major demographic deviations in age, gender, or race were absent (Table 2a, 2b). The pre-module mean for the control group was $30.00(S D=$ 4.993, $N=16)$ and the post-module mean was $30.69(S D=4.110, N=16)$. The experimental group exhibited a pre-module mean of $28.31(S D=2.213, N=16)$ and a post-module mean of $32.69(S D=3.439$, 
$N=16$ ). A two-tailed independent sample $t$-test was conducted on the gain scores of the two groups which identified a significant difference between the two means $[t(30 \mathrm{df})=2.797, p<0.05]$.

\section{Discussion}

Affirmation of the hypothesis was statistically supported by the data. The study found that perceived selfefficacy scores of students who participated in the PBL module were higher than their counterparts who attended the unmodified laboratory session. These results were congruent with previous research findings outlined by Dunlap (1). Students in the PBL session revealed an increased perceived ability to successfully perform effectively under diverse circumstances upon completing the module. Conversely, students who utilized the traditional method of instruction portrayed no significant change in perceived self-efficacy either positive or negative.

Following the guise of the PBL approach, students encountered the scenario and worked collaboratively to identify prominent issues, analyze data, problem solve, and reflect on newly acquired knowledge. The environment of PBL, utilizing reality-based problems, collaboration, and reflection provides individuals with performance accomplishments and vicarious experiences (1). Active engagement and diligent use of various resources ultimately resulted in successful performance. This demonstration of behavioral success likely contributed to increased efficacy appraisals. Furthermore, observing accomplishments of classmates may have contributed to raising student perceptions of their own abilities to perform effectively.

The results of this study provide further evidence to support PBL as a method that may enhance student perceived self-efficacy. Although requiring a significant investment in time and effort, PBL has revealed the potential to influence a major cognitive element of behavioral performance. As educators, we seek to optimize student performance while fostering confidence in learned skills and abilities. Particularly in healthcare, one's perceived ability to perform effectively under diverse circumstances may have a significant impact on patient outcomes. By improving student's perceived self-efficacy, educators will increase the probability that students will employ newly acquired proficiencies, apply significant effort, and 
persevere when faced with challenges $(4,5)$. Therefore, PBL may prove to be a viable alternative or supplement to non-problem-based instructional approaches in the undergraduate nursing setting.

\section{Limitations and Suggestions for Further Study}

Conducting the study in one setting using a small nonprobability sample may have influenced the applicability of results. Consequently, generalizability may have been impaired limiting the extension of implications to a larger population. Additionally, the researcher conducting the PBL module may have influenced student perceived self-efficacy. Students in the PBL group potentially received an increased amount of attention when compared to the control group. To further examine PBL in relation to selfefficacy, recommendations for future research include replication using a larger sample size in multiple settings over a full semester-length course.

\section{Conclusion}

Various studies support the efficacy of PBL as a student-centered method of teaching and learning. This study looked beyond pure knowledge acquisition and addressed behavioral perceptions associated with concepts learned. Nursing students participating in the PBL exercise clearly portrayed an increased degree of self-efficacy compared to their counterparts. Though additional research is certainly warranted, nurse educators seeking to add to their repertoire of teaching techniques may consider utilizing PBL as a viable pedagogical approach. 


\section{References}

1. Dunlap, J. C. (2005). Problem-based learning and self-efficacy: How a capstone course prepares students for a profession. Educational Technology Research and Development, 53(1), 65-85.

2. National League for Nursing (2005). The scope of practice for academic nurse educators. New York, NY: NLN

3. Duch, B. J., Groh, S. E., Allen D. E. (Eds.). (2001).The power of problem-based learning. Sterling, VA: Stylus Publishing.

4. Bandura, A. (1977). Self-efficacy: Toward a unifying theory of behavioral change.

Psychological Review, 84(2), 191-215.

5. Bandura, A. (1986). Social foundations of thought and action: A social cognitive theory. Englewood Cliffs, NJ: Prentice-Hall.

6. Beers, G. (2005). The effect of teaching method on objective test scores: Problem-based learning versus lecture. Journal of Nursing Education, 44(7), 305-309.

7. DeMarco, R., Hayward, L., \& Lynch, M. (2002). Nursing students' experiences with and strategic approaches to case-based instruction: A replication and comparison between two disciplines. Journal of Nursing Education, 41(4), 165-174.

8. Hwang, S. Y., \& Kim, M. J. (2006). A comparison of problem-based learning and lecture-based learning in an adult health nursing course. Nurse Education Today, 26, 315-321.

9. Siu, H., Laschinger, H., Vingilis, E. (2005). The effect of problem-based learning on nursing students' perceptions of empowerment. Journal of Nursing Education, 44(10), 459-469.

10. Baker, C. J. (2000). Problem-based learning for nursing: Integrating lessons from other disciplines with nursing experience. Journal of Professional Nursing, 16(2), 258-266.

11. Woody, M., Albrecht, S., Hines, T., \& Hodgson, T. (1999). Directed case studies in 
baccalaureate nursing anatomy and physiology. Journal of Nursing Education, 38(8), 383-386

12. Beers, G., \& Bowden, S. (2005). The effect of teaching method on long-term knowledge retention. Journal of Nursing Education, 44(11), 511-514.

13. Greg, R. (1993). Student perceptions about self-directed learning in a professional course implementing problem-based learning. Studies in Higher Education, 18(1), 307-318.

14. Goldenberg, D., Andrusyszyn, M., Iwasiw, C. (2003). The effect of classroom simulation on nursing students' self-efficacy related to health teaching. Journal of Nursing Education, 44(7), 310-314.

15. Bastable, S. (2003). Nurse as educator: Principles of teaching and learning for mursing practice $\left(2^{\text {nd }}\right.$ ed.). Sudbury, MA: Jones and Bartlett Publishers.

16. Smith, M. J., \& Liehr, P. R. (Eds.). (2003). Middle range theory for nursing. New York, NY: Springer Publishing Company.

17. Schwarzer, R., \& Jerusalem, M. (1995). Generalized Self-Efficacy scale. In J. Weinman, S. Wright, \& M. Johnston, Measures in health psychology: A user's portfolio. Casual and control beliefs (pp. 35-37). Windsor, UK: NFER-NELSON. 
Appendix A

Problem-Based Learning Module:

Central Venous Catheters

Module Learning Outcomes:

1. Identify the purpose(s) of central venous access devices (CVAD).

2. Differentiate between CVADs and peripheral lines.

3. Compare various central venous access devices (CVAD).

4. State the advantages and disadvantages of each of the 4 sites commonly used for CVADs.

5. Identify 6 potential complications of CVADs, as well as preventative measures and interventions. 
Note: This problem-based learning activity is a supplement to the regularly assigned skills module and does not take the place of homework outlined in the Nursing 155 syllabus.

\section{Scenario Part 1}

You are a registered nurse working on a medical-surgical floor at a local hospital. You have just received report from the emergency room (ER) regarding a 23 year old male named John who was involved in a motor vehicle crash. John was a restrained passenger and sustained blunt abdominal trauma. John's CT report identifies a lacerated spleen. According to the trauma surgeon, surgical intervention is not indicated at this time. The patient is tachycardic with a heart rate ranging from 110 to 120 and is complaining of generalized abdominal pain at 4/10. Hemoglobin and hematocrit levels drawn on admission were low normal. John is alert and oriented, on $2 \mathrm{~L} \mathrm{NC}$ with an oxygen saturation ranging from $98 \%$ to $100 \%$. Other vital signs and systems are within normal limits and John has a 20 gauge IV in his left forearm. Fifteen minutes after report, the ER nurse arrives to your floor with John resting on a gurney. John transfers to your floor bed without incident and you apply monitoring devices. As the ER nurse is leaving, he states that a second set of hemoglobin and hematocrit levels are pending. As soon as you finish your primary assessment, the laboratory calls you with a critical hemoglobin level of $8.8 \mathrm{~g} / 100 \mathrm{ml}$ and hematocrit of $26.4 \%$. You notify the attending physician and he tells you that he will come momentarily to insert a central venous access device and write further orders.

Discussion questions:

1. What are some reasons for the placement of a central venous access device in John?

2. Why insert a central venous access device as opposed to additional peripheral intravenous lines?

3. What type of central venous access device(s) would you have ready at the bedside for the physician?

4. What are potential insertion sites on John for central venous access?

5. After the venous access device is inserted, what supplies will you need to properly dress the site?

6. What are potential complications John may experience possessing a central venous access device?

7. Under what circumstances would a chest $\mathrm{x}$-ray be ordered after insertion and why?

8. What nursing diagnosis will apply to John after a central venous catheter is inserted? 


\section{Scenario Part 2}

John has been in the hospital for seven days and has not required surgery for his splenic laceration. The right subclavian central line you assisted to insert remains in place. His hemoglobin and hematocrit levels stabilized after 4 units of packed red blood cells administered over the first few days of his hospitalization. You assess John and he complains of having a poor appetite and feeling continually "worn out" and "hot". Additionally, your assessment reveals stable vital signs except for a temperature of $100.8^{\circ}$ $\mathrm{F}$, and a resting heart rate of 95 to 100 beats per minute. The central venous catheter appears red around the insertion site. John complains of tenderness when light palpation is applied to the area surrounding the catheter. You notice that the dressing was changed four days ago. Looking at his laboratory trends over the last several days you notice his white blood cell count rising and today it is $19,000 / \mathrm{mm}^{2}$.

Discussion questions:

1. What potential complication of having a central venous access device may John be experiencing?

2. What other signs and symptoms may you see with this complication?

3. What are some activities by healthcare staff that may have led to John's current condition?

4. When was the central venous catheter dressing supposed to be changed?

5. How much longer can John's central venous access device stay in place?

6. What nursing actions are necessary to address John's current condition?

7. If you were too busy to address John's condition how may his status further deteriorate?

8. How would you revise John's nursing care plan? 


\section{Scenario Part 3}

It has been several days since you have had John as a patient and you intend to stop by his room and say hello when you have a free moment. You are concentrating intently on charting when you feel a tap on your shoulder. You look up and see John with a big smile. Behind John is his family, he thanks you for your attentive care and excitedly says he has been discharged home! He explained that after you removed the central line and cultured the tip, it tested positive for bacteria. He further said that he received antibiotics and felt much better within a few days. Thanking you again and receiving appreciative smiles from John's family you see your former patient leave the floor.

Discussion questions:

1. Name the most memorable element of central venous catheters you personally learned from this activity?

2. When caring for patients with central venous access catheters what are some key elements to be aware of?

3. If during your clinical rotation you see a student or nurse utilizing poor technique in caring for a central venous access catheter how would you approach that situation? 
Thank You for Participating!

Appendix B

General Perceived Self-Efficacy Scale (Schwarzer \& Jerusalem, 1995).

Assigned Identification Number:

Directions: Each of these questions should be answered in the context of the Central Venous Catheter module. Write your response to each question in the space provided to the left of each question. Please be sure that all ten questions are answered, and that your assigned identification number is in the appropriate space provided above.

Response Format:

$1=$ Not at all true

$$
2=\text { Hardly true } \quad 3=\text { Moderately true } \quad 4=\text { Exactly true }
$$

I can always manage to solve difficult problems if I try hard enough.

If someone opposes me, I can find the means and ways to get what I want.

It is easy for me to stick to my aims and accomplish my goals.

I am confident that I could deal efficiently with unexpected events.

Thanks to my resourcefulness, I know how to handle unforeseen situations.

I can solve most problems if I invest the necessary effort.

I can remain calm when facing difficulties because I can rely on my coping abilities.

When I am confronted with a problem, I can usually find several solutions.

If I am having trouble, I can usually think of a solution.

I can usually handle whatever comes my way. 
Appendix C

Demographic Survey

Age

Gender

a. Male

b. Female

Ethnicity (Please circle only one)

a. American/Black

b. Alaskan/Native American

c. Asian/Pacific Islander

d. Mexican American/Hispanic

e. White

f. Other 


\begin{tabular}{|ll|r|r|}
\hline Student Group Assignment & $\begin{array}{l}\text { Pre- } \\
\text { Interventional } \\
\text { Self-Efficacy }\end{array}$ & $\begin{array}{l}\text { Post- } \\
\text { Interventional } \\
\text { Self-Efficacy }\end{array}$ \\
\hline & & & \\
Participated in & 16 & \\
Problem-Based & $\mathrm{N}$ & 28.3 & 32.69 \\
Learning Activity & Mean & 2.2 & 3.4 \\
& Standard Deviation & 24 & 27 \\
& Minimum & 40 \\
& Maximum & 31 & \\
& & & \\
Participated in & & & \\
Non-Problem-Based & & 30 & \\
Approach & N & 5 & \\
& Mean & 22 & \\
& Standard Deviation & 38 & \\
& Minimum & 3.1 \\
& Maximum & & 38 \\
& & & \\
\hline
\end{tabular}

Table 1. Self-Efficacy Scores 
Table 2a. Age and Gender Distribution

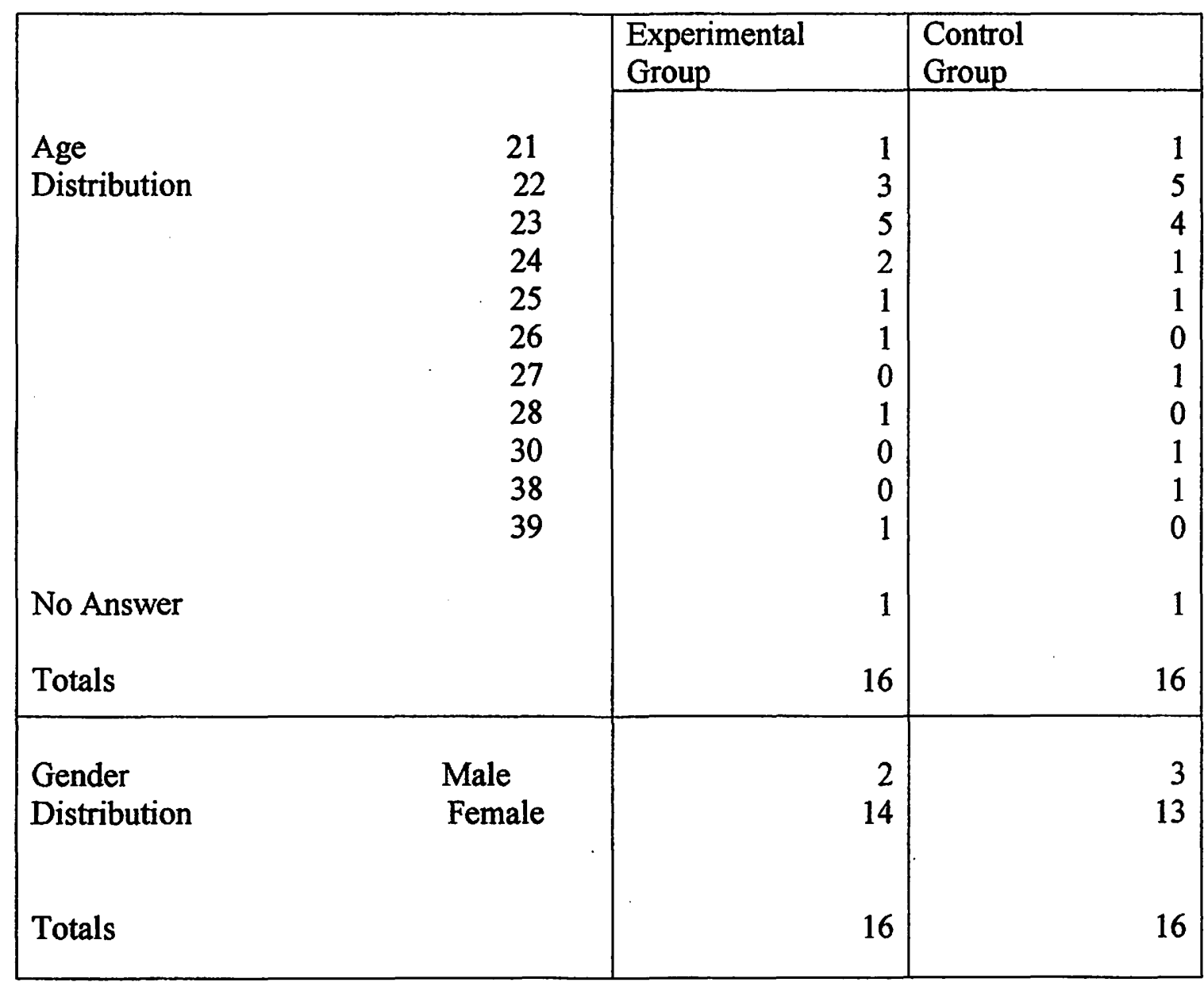




\begin{tabular}{|ll|l|l|}
\hline & & $\begin{array}{l}\text { Experimental } \\
\text { Group }\end{array}$ & $\begin{array}{l}\text { Control } \\
\text { Group }\end{array}$ \\
\cline { 3 - 4 } Ethnicity & African American & 0 & 1 \\
& Asian/Pacific Islander & 10 & 9 \\
& Mexican American & 2 & 2 \\
& White & 4 & 1 \\
Other & 0 & 3 \\
Totals & & 16 & 16 \\
& & & \\
& & & \\
\end{tabular}

Table 2b. Ethnic Distribution 


\section{Phyllis Connolly}

\section{From:}

Sent: Wednesday, May 16, 2007 9:15 PM

To: Phyllis Connolly

Subject: FW: Submission Confirmation

Attachments: Title(manuscript).doc

Hello Dr. Connolly,

This e-mail has the forwarded message from Nurse Educator confirming my manuscript submission. Additionally, I have attatched the title page of my manuscript. I will place hard copies of this material in your SJSU mailbox as well.

Thank you for all your help!

Joel Romero

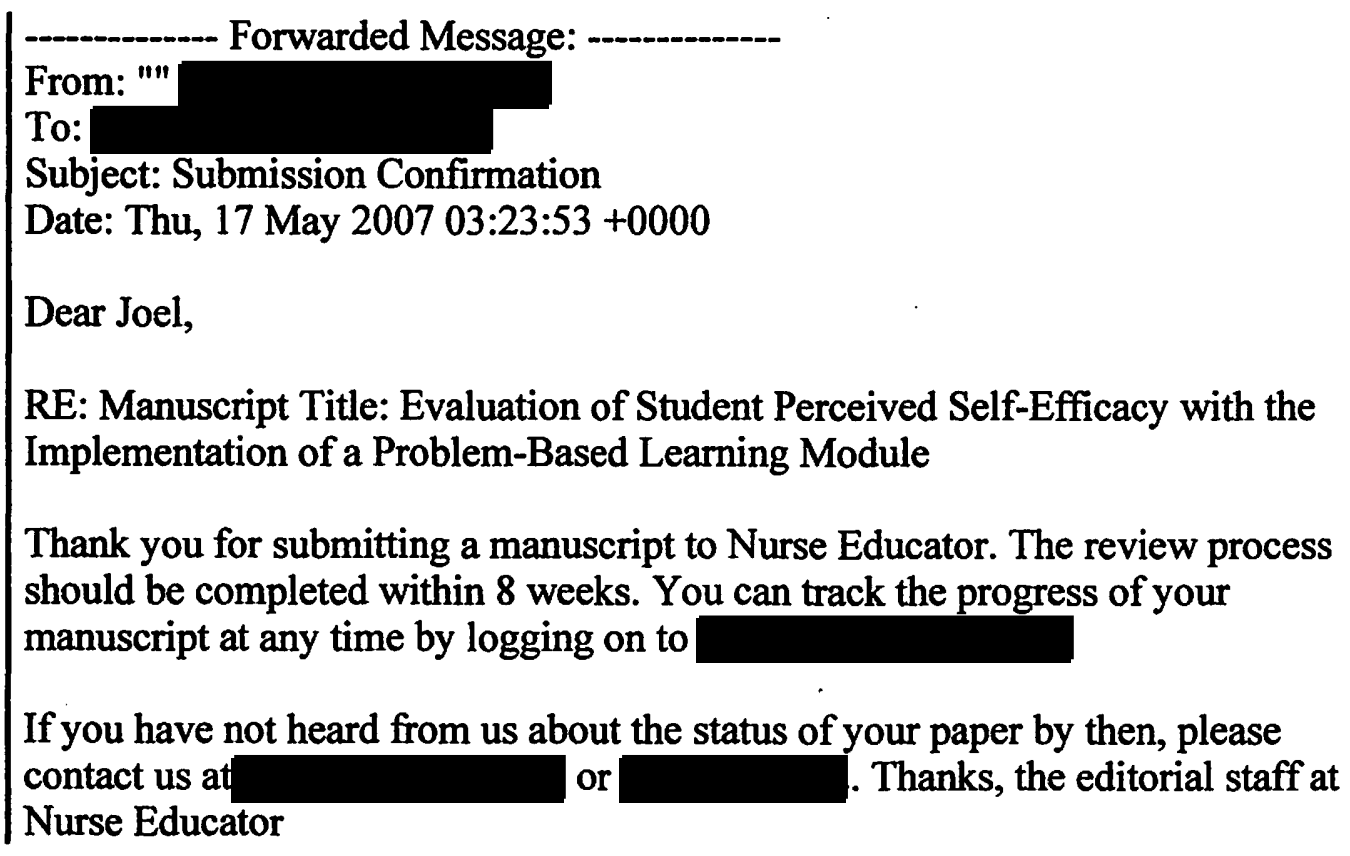

